\title{
Consumption of fruit and vegetables: the ROUND (woRld map of cOnsUmption of fruit and vegetables and Nutrient Deficits) project
}

\author{
Dario Gregori ${ }^{1}$, Megan French ${ }^{2}$, Silvia Gallipoli ${ }^{2}$, Giulia Lorenzoni ${ }^{1}$ and Marco Ghidina ${ }^{2}$ \\ ${ }^{1}$ Unit of Biostatistics, Epidemiology and Public Health, University of Padova, Padova, Italy and \\ ${ }^{2}$ Zeta Research Ltd, Trieste, Italy
}

\section{Abstract}

Introduction: In 2017, 11 million deaths and 255 million DALYs were attributable to dietary risk factors, with low intake of fruits being the leading risk factor globally ${ }^{(1)}$. Adequate F\&V consumption is considered in the WHO (2010) report on non-communicable diseases (NCDs) to reduce the risk for NCDs (e.g., obesity, type 2 diabetes, cardiovascular disease, and some cancers). Recommended daily intake of $F \& V$ vary from the WHOs ${ }^{3} 400 \mathrm{~g} /$ day to $\sim 750 \mathrm{~g}$ /day (including potatoes) in the U.S ${ }^{(2)}$, but per capita availability is not always met, even in Europe ${ }^{(3)}$. Increased availability, affordability, and consumption of F\&V is part of policy options in the WHOs 2013-2020 global action plan for the prevention and control of NCDs. The aim of the ROUND project is to evaluate consumption of $\mathrm{F} \& \mathrm{~V}$ in adults between countries and to identify, characterize, and map interactively vulnerable population groups and nutrient deficiencies, thus providing a useful tool for research and policy.

Methods: Data relating to adult consumers from dietary surveys in Europe and the United States were assessed. Analyses were performed using Bayesian hierarchical models.

Results: Data for adults from surveys contained within the European Food Safety Authority (EFSA) Comprehensive European food consumption database and U.S Food Intakes Converted to Retail Commodities Database FICRCD were included in the analysis. Mean per capita daily consumption of total fruit, vegetables (excluding starchy roots/tubers), fresh legumes, and F\&V juice in Europe ranges from $261 \mathrm{~g} / \mathrm{d}$ in Latvia (2008) to $552 \mathrm{~g} / \mathrm{d}$ in Romania (2012), and in the U.S from 560 g/d (2005/06) to 616 g/d (2001/02). Mean fruit intake (excluding juice) alone ranges from $85 \pm 98 \mathrm{~g} / \mathrm{d}$ in Ireland (2008) to $226 \pm 231 \mathrm{~g} / \mathrm{d}$ in Estonia (2013), mean vegetable intake ranges from $62 \pm 58 \mathrm{~g} / \mathrm{d}$ in Sweden (1997) to $382 \pm 194 \mathrm{~g} / \mathrm{d}$ in Romania (2012), and mean F\&V juice intake ranges from $6 \pm 32 \mathrm{~g} / \mathrm{d}$ in Romania (2012) to $223 \pm 368 \mathrm{~g} / \mathrm{d}$ in Germany (2007).

Discussion: Data on adult F\&V consumption varies across countries and are often below recommended intake [3]. Identification and interactive mapping of low $\mathrm{F} \& \mathrm{~V}$ consuming regions highlights vulnerable population groups which provides a useful tool for related research and policy.

\section{Conflict of Interest}

There is no conflict of interest

\section{References}

1. Afshin et al. (2017) doi:10.1016/S0140-6736.

2. U.S.D.A. (2015-2020) Dietary Guidelines for Americans.

3. WHO (2000) CINDI Dietary health guide. 